\title{
Adsorption Properties of Methyl Orange in Water by Sheep Manure Biochar
}

\author{
Yixin Lu ${ }^{1,2}$, Jiao Chen ${ }^{1,2}$, Yang Bai, ${ }^{1,2}$, Jinzhang Gao ${ }^{1}$, Mingjiang Peng1* \\ ${ }^{1}$ College of Architectural and Environmental Engineering, Chengdu Technological University, Chengdu, China \\ ${ }^{2}$ Center of Big Data for Smart Environmental Protection, Chengdu Technological University, Chengdu, China
}

Received: 14 June 2018

Accepted: 24 September 2018

\begin{abstract}
Sheep manure was used to prepare biochar under pyrolysis temperature of $600^{\circ} \mathrm{C}$. The structural features of biochar were characterized by elemental analysis, BET analysis and scanning electron microscopy. The effects of $\mathrm{pH}$, biochar dosage, adsorption time, temperature on adsorption of methyl orange (MO) in water by sheep manure biochar, as well as its adsorption mechanism, were investigated via batch experiments. The results showed that the sheep manure biochar had large specific surface area, abundant hole structure and high aromaticity and polarity. When temperature was $25^{\circ} \mathrm{C}, \mathrm{MO}$ concentration was $20 \mathrm{mg} / \mathrm{L}$, initial $\mathrm{pH}$ was 4.0 , and biochar dosage was $0.6 \mathrm{~g} / \mathrm{L}$, the adsorption achieved balance at about $250 \mathrm{~min}$, and the MO removal rate reached to $92.55 \%$. Pseudo second-order kinetic model and Langmuir model could more accurately describe the adsorption behavior of MO onto sheep manure biochar, and the theoretical maximum adsorption capacity was 42.513 to $45.563 \mathrm{mg} / \mathrm{g}$. Besides, the process is a favorable adsorption. Thermodynamic studies showed that the adsorption was a spontaneous, endothermic and entropy-increasing process. Sheep manure biochar could be used as a good adsorption material for MO in water, which achieved the goal of controlling waste by waste.
\end{abstract}

Keywords: biochar, sheep manure, meheyl orange, adsorption

\section{Introduction}

As a commonly used azo dye, methyl orange (MO) has been widely used in the printing and dyeing textile industries. MO is difficult to be biomedically degraded due to its complex aromatic structure [1]. With its usage increased, the pollution of methyl orange dye wastewater has been a growing problem, and there's an urgent need to develop effective counter-measures. Currently, methods of treating dye wastewater mainly

*e-mail: 244535189@qq.com include the adsorption method [2-5], photocatalysis $[6,7]$ and chemical oxidation $[8,9]$. Among them, the adsorption method has been widely used because of its smaller footprint, strong control ability and good treatment efficiency. The research and development of new efficient and cheap adsorption materials has become a hot topic.

Biochar is a carbonaceous matter of high aromatase prepared by biomass pyrolyzed under the condition of limiting oxygen or oxygen-free, with the characteristics of well-developed pore structure, rich functional groups and large ion exchanges [10-12]. As a new kind of multi-functional material, biochar has been widely used in returning farmland to sequester carbon, soil 
improvement and pollutant adsorption in recent years [13-16]. However, there have been few reports on the preparation of biochar and the use of animal wastes as raw materials to absorb MO. With the increase of livestock breeding in China, pollution by livestock and poultry manure has been increasing. According to the forecast analysis, the amount of livestock and poultry waste in China will reach 2.98 million tons by 2020 , so new approaches are urgently needed to solve the environmental pollution problems caused by livestock and poultry excrement.

Therefore, this study prepared biochar from sheep manure and used it in the adsorption of MO in water. Based on the analysis of the characteristics of the biochar structure, the main factors affecting the effect of MO adsorption were investigated, and the adsorption mechanism was analyzed through kinetic and thermodynamic models. The purpose was to provide a new adsorption material for the treatment of methyl orange wastewater, and to provide a scientific basis for the new resource utilization method of sheep manure.

\section{Materials and Methods}

\section{Reagents and Instruments}

Main reagents: The methyl orange (molecular formula: $\mathrm{C}_{14} \mathrm{H}_{14} \mathrm{~N}_{3} \mathrm{SO}_{3} \mathrm{Na}$ ) purchased from Tianjin Ruijin Chemical Pharmaceutical Co. Ltd was confected to $1000 \mathrm{mg} / \mathrm{L}$ as reserve solution and later diluted for the experimental needs. All the $\mathrm{NaOH}$ and $\mathrm{HCl}$ involved were analytically pure and the water was deionized.

Main instruments are: muffle furnace (SG-XL1200); acidimeter (PHS-3C); electro- thermostatic blast oven (DHG-9030A); ultraviolet and visible spectrophotometer (UV-1800PC); vapour-bathing constant temperature vibrator (THZ-82); table model high-speed centrifuge (2-16P); electronic analytical balance (JA5003); elemental analyzer (VARIO EL Cube); surface area analyzer (NOVA4000e); and FESEM (SUPRA40).

\section{Preparation of Biochar}

Sheep manure was collected from a farm in Yaan, Sichuan Province, impurities were picked out and it was spread to dry. The manure was processed by a pulverizer and ground through an 80-mesh sieve and put in an oven at $65^{\circ} \mathrm{C}$ to dry. It was weighed and an appropriate amount of dried goat dung was put in a crucible, compacted and covered, then put in the muffle furnace heated to $600^{\circ} \mathrm{C}$ at the heating rate of $15^{\circ} \mathrm{C} / \mathrm{min}$ and maintained constant temperature for $150 \mathrm{~min}$. It was cooled to room temperature and $\mathrm{HCl}$ was added to the pyrolysis product at a solid-to-liquid ratio of $1: 20$, and triplicated the shock cleaning to remove ash at $150 \mathrm{r} / \mathrm{min}$ for $30 \mathrm{~min}$ each in $25^{\circ} \mathrm{C}$. Water washing to neutral using deionized water, and sifted and dried in an oven at $105^{\circ} \mathrm{C}$. The bio-char from sheep manure was prepared after the products cooled and through 100 mesh, and packed it in an amber wide-mouth packers.

\section{Experimental Method of Adsorption}

(1) The effect of initial $\mathrm{pH}$ value was: $50 \mathrm{~mL} \mathrm{MO}$ solution of $20 \mathrm{mg} / \mathrm{L}$ was added to a $100 \mathrm{~mL}$ conical flask, then adjusted the initial $\mathrm{pH}$ value from 2.0 to 10.0 by $\mathrm{HCl}$ and $\mathrm{NaOH}$ of $1 \mathrm{~mol} / \mathrm{L}$. The sheep manure biochar weight $0.04 \mathrm{~g}$ was added to each sample and oscillated at $200 \mathrm{r} / \mathrm{min}$ at $25^{\circ} \mathrm{C}$ for $300 \mathrm{~min}$ before centrifuging at $4000 \mathrm{r} / \mathrm{min}$ for $10 \mathrm{~min}$. The absorbance of the supernate was measured at a wavelength of $462 \mathrm{~nm}$ and the concentration of the remaining MO in the solution was calculated.

(2) The effect of biochar dosage was: $50 \mathrm{~mL} \mathrm{MO}$ solution of $20 \mathrm{mg} / \mathrm{L}$ was added to a $100 \mathrm{~mL}$ conical flask. We adjusted the $\mathrm{pH}$ to 4.0 and added 0.01 to $0.09 \mathrm{~g}$ biochar to each sample, oscillated at $200 \mathrm{r} / \mathrm{min}$ at $25^{\circ} \mathrm{C}$ for $300 \mathrm{~min}$ before repeating step (1).

(3) The effect of adsorption time was: $50 \mathrm{~mL} \mathrm{MO}$ solution of $20 \mathrm{mg} / \mathrm{L}$ was added to a $100 \mathrm{~mL}$ conical flask. We adjusted the $\mathrm{pH}$ to 4.0 and $0.03 \mathrm{~g}$ biochar was added and oscillated at $200 \mathrm{r} / \mathrm{min}$ in $25^{\circ} \mathrm{C}$ for 30 to $300 \mathrm{~min}$ before repeating step (1).

(4) The effect of initial concentration and temperature of MO was: $50 \mathrm{~mL}$ MO solution with the initial concentration ranging 10 to $80 \mathrm{mg} / \mathrm{L}$ were added to a $100 \mathrm{~mL}$ conical flask. We adjusted the $\mathrm{pH}$ to 4.0 and $0.03 \mathrm{~g}$ biochar was added, oscillated at $200 \mathrm{r} / \mathrm{min}$ at 25,35 and $45^{\circ} \mathrm{C}$ for $250 \mathrm{~min}$ before repeating step (1).

\section{Testing and Analysis Method}

The $\mathrm{C}, \mathrm{H}, \mathrm{N}$, and $\mathrm{O}$ content of sheep manure biochar was tested by elemental analyzer while its specific surface area, total pore volume and average pore size were measured by the BET method. A field emission scanning electron microscope was also adopted to analyze surface topography. The adsorption quantity $(q, \mathrm{mg} / \mathrm{g})$ and removal rate $(r, \%)$ of the $\mathrm{MO}$ by biochar were calculated using the following formula:

$$
\begin{gathered}
q=\left(c_{0}-c_{\mathrm{t}}\right) \times V / m \\
r=\left(c_{0}-c_{\mathrm{t}}\right) \times 100 \% / c_{0}
\end{gathered}
$$

$c_{0:}$ initial concentration of $\mathrm{MO}, \mathrm{mg} / \mathrm{L}$

$c_{\mathrm{t}:}$ concentration of $\mathrm{MO}$ at time $\mathrm{t}, \mathrm{mg} / \mathrm{L}$

$\mathrm{V}$ : volume of $\mathrm{MO}$ solution, $\mathrm{mL}$

$\mathrm{m}$ : quantity of sheep manure biochar, $\mathrm{g}$ 


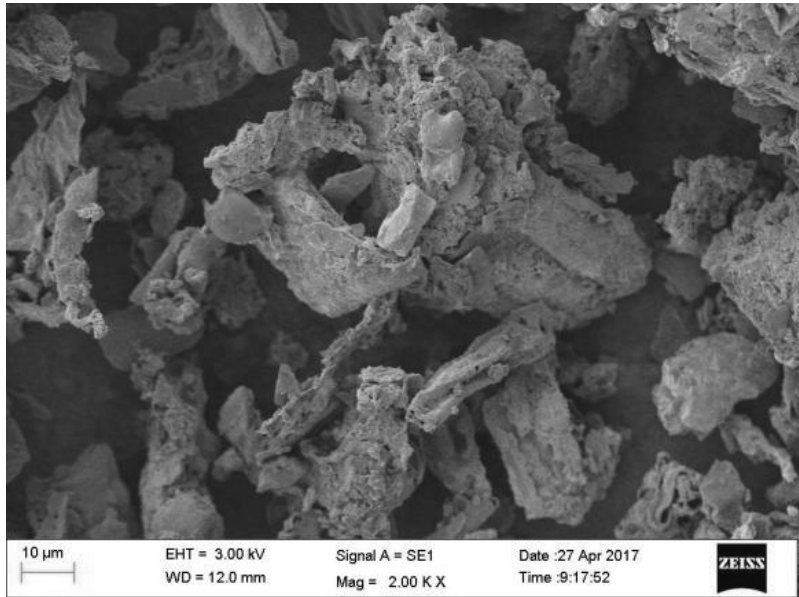

Fig. 1. SEM of sheep manure biochar (salient observations: rough surface, a large number of irregular micropores).

\section{Results and Discussion}

\section{The Structural Characteristics of Biochar}

According to the elemental analysis results of the sheep manure biochar, the mass fractions of $\mathrm{C}, \mathrm{O}$, $\mathrm{N}$ and $\mathrm{H}$ were $63.25 \%, 12.09 \%, 2.49 \%$ and $2.21 \%$. It can be seen that the highest content in sheep manure biochar was $\mathrm{C}$, followed by $\mathrm{O}$ and $\mathrm{N}$. Going forward, the atomic ratios of $\mathrm{H} / \mathrm{C}$ and $\mathrm{O} / \mathrm{C}$ were calculated as 0.035 and 0.191 . According to related literatures, the aromaticity of biochar could be judged by the $\mathrm{H} / \mathrm{C}$ ratio. The $\mathrm{H} / \mathrm{C}$ ratio was less than 0.6 , indicating that there were more aromatic structures [17, 18]. The polarity of biochar could be judged according to the $\mathrm{O} / \mathrm{C}$ ratio. The polarity was higher and the biochar had a longer half-life cycle when the ratio was less than $2[19,20]$. Therefore, the sheep manure biochar possessed higher aromaticity and polarity. According to the BET results, the specific surface area, total pore volume and average pore diameter were $181.76 \mathrm{~m}^{2} / \mathrm{g}, 0.245 \mathrm{~cm}^{3} / \mathrm{g}$ and $11.91 \mathrm{~nm}$, respectively, indicating that the biochar had a large specific surface area and developed pore structure. Combined with the SEM analysis results in Fig. 1, the sheep manure biochar prepared in this study not only had a rough surface, but also spread a large number of irregular micropores, which provided a good basis for the adsorption of MO in the water.

\section{Effect of Initial pH on Adsorption Effect}

The effect of initial $\mathrm{pH}$ on adsorption was shown in Fig. 2, where $q_{\mathrm{e}}$ and $r$ respectively expressed the equilibrium adsorption amount and removal rate of MO by the sheep manure biochar. As could be seen from Fig. 2, with the increase of $\mathrm{pH}$ value of the solution, the adsorption quantity and removal rate of MO gradually increased. $\mathrm{MO}$ was mainly in the form of $\mathrm{MO}^{-}$when its acidic dissociation constant was 3.4. While in acidic conditions, biochar was combined with $\mathrm{MO}^{-}$through

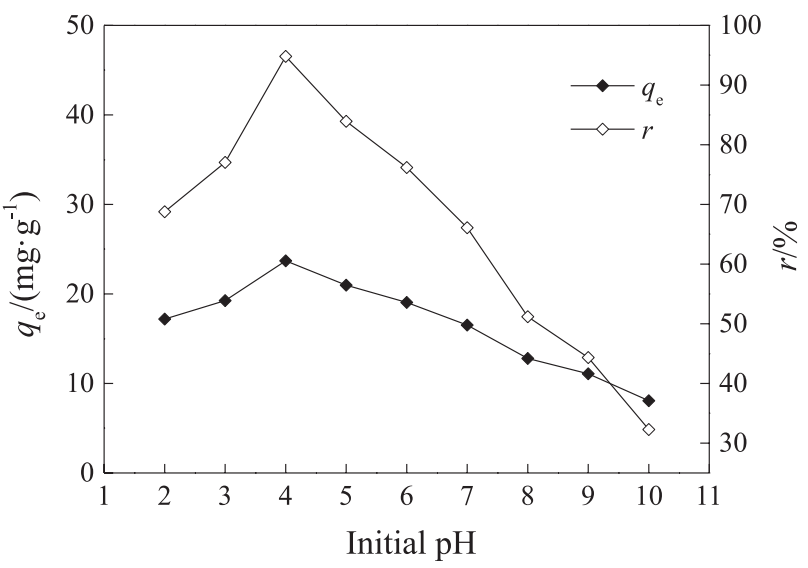

Fig. 2. Effect of $\mathrm{pH}$ value on adsorption performance.

electrostatic interaction due to the protonation of surface functional groups. Therefore, the optimum $\mathrm{pH}$ for adsorption was 4.0 with the adsorption quantity of $23.7 \mathrm{mg} / \mathrm{g}$ and removal rate of $94.8 \%$. With the increase of $\mathrm{pH}$, the degree of biochar protonation decreased and the electrostatic effect weakened, resulting in a decline of adsorption quantity. In addition, $\mathrm{OH}^{-}$started competing with $\mathrm{MO}^{-}$for the active points on biochar when $\mathrm{pH}$ was greater than 7.0, which further weakened the adsorption effect.

\section{The Effect of Input Dosage on Adsorption}

The influence of different dosages of biochar on the adsorption effect of MO is shown in Fig. 3. It could be seen that the removal rate of MO was gradually increasing as the biochar increased from $48.95 \%$ to $99.25 \%$. The removal rate of MO increased significantly with the increase of biochar when the input dosage of biochar was 0.2 to $0.6 \mathrm{~g} / \mathrm{L}$, while the removal rate of MO tended to flatten when the input dosage of biochar was more than $0.6 \mathrm{~g} / \mathrm{L}$. However, with the amount of input biochar further increased, the adsorption $\mathrm{MO}$ gradually decreased from $48.950 \mathrm{mg} / \mathrm{g}$ to $11.027 \mathrm{mg} / \mathrm{g}$.

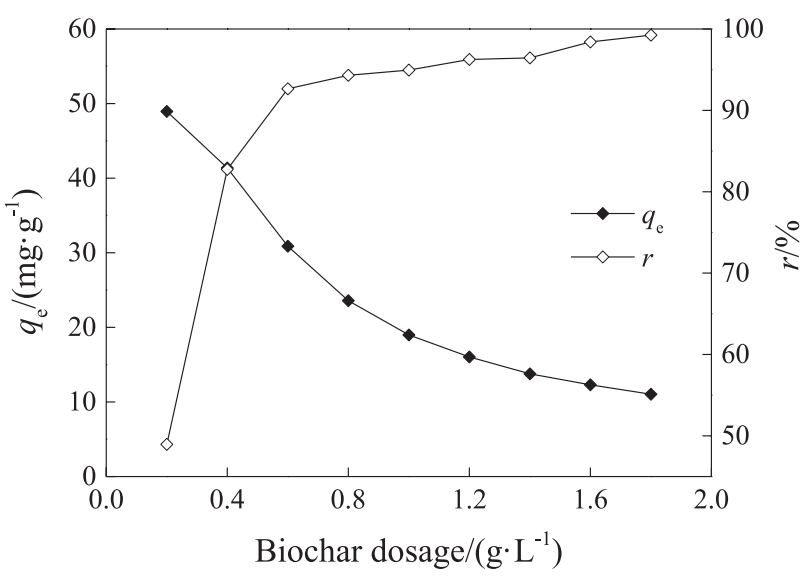

Fig. 3. Effect of dosage on adsorption performance. 
According to the analysis, because the total amount of MO in the solution was limited, when the amount of biochar was insufficient, a large number of MO could not be effectively adsorbed by biochar and lead to the low removal rate. However, overloading biochar could lead to excessive adsorption points, resulting in the decrease of MO adsorbed by the unit mass biochar. We took the adsorption effect and economy into overall consideration, and the subsequent experimental selection of the amount of the increase was 0.6, where the MO adsorption quantity and removal rate were $30.883 \mathrm{mg} / \mathrm{g}$ and $92.65 \%$, respectively.

\section{Adsorption Dynamics Analysis}

The influence of adsorption time on the adsorption effect of MO was shown in Fig. 4. To further analyze the adsorption process of sheep manure biochar on MO, pseudo first-order kinetic model (formula 3), pseudo second-order kinetic model (formula 4) and particle diffusion model (formula 5) [21-23] were used to fit the experimental data, and the results are shown in Table 3 .

$$
\begin{gathered}
\ln \left(q_{e}-q_{t}\right)=\mathrm{h} q_{e}-k_{1} t \\
\mathrm{t} / q_{t}=\mathrm{t} / q_{e}+1\left(k_{2} q_{\mathrm{e}}^{2}\right) \\
q_{t}=k_{3} t^{0.5}+C
\end{gathered}
$$

$q_{\mathrm{e}:}$ adsorption of $\mathrm{MO}$ at equilibrium, $\mathrm{mg} / \mathrm{g}$

$q_{\mathrm{t}:}$ adsorption of $\mathrm{MO}$ at time $\mathrm{t}, \mathrm{mg} / \mathrm{g}$

$\mathrm{t}$ : adsorption time, $\min$

$k_{1,}$ reaction rate constant, $\min ^{-1}$

$k_{2}$. reaction rate constant, $\mathrm{g} /(\mathrm{mg} \cdot \mathrm{min})$

$k_{3:}$ reaction rate constant, $\mathrm{mg} /\left(\mathrm{g} \cdot \mathrm{min}^{0.5}\right)$

$C$ : constant

As shown in Fig. 4, the first 60 min belonged to the rapid adsorption phase, and the adsorption of biochar to MO has increased significantly as time goes on, and MO adsorption reached $64.78 \%$ compared with the equilibrium adsorption capacity. This was due to the high rate of adsorption because of the abundant adsorption points on biochar surface. The section of 60 to $250 \mathrm{~min}$ belonged to the slow diffusion phase, as the extension of adsorption time, the active adsorption points on the biochar were gradually occupied and MO began to spread slowly inside its internal air void, which lead to the increase in adsorption slowed down. The section of 250 to $600 \mathrm{~min}$ belonged to the

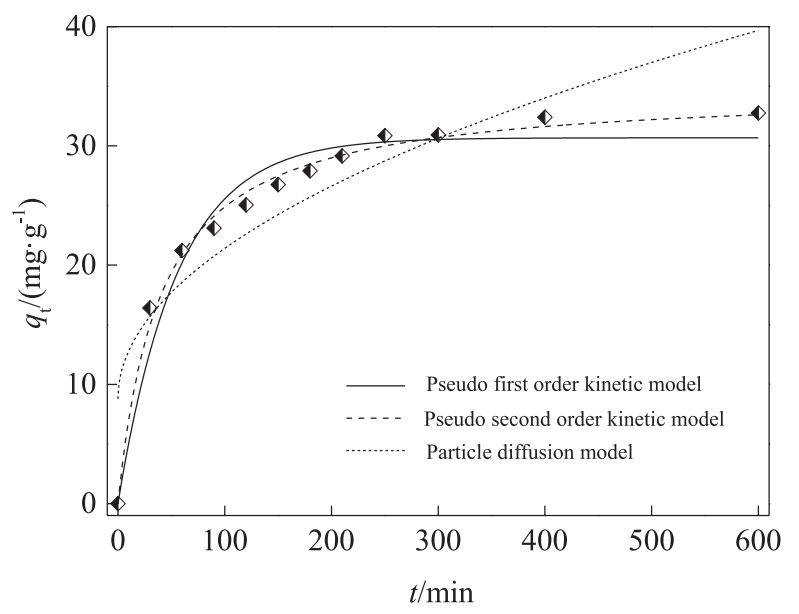

Fig. 4. Fitting curves of adsorption kinetics.

Adsorption equilibrium phase, the adsorption capacity of biochar was close to saturation and the increase of adsorption quantity waned with time. Therefore, $250 \mathrm{~min}$ was selected as the adsorption time for the follow-up experiments, and the adsorption and removal rates of pollutants were $30.85 \mathrm{mg} / \mathrm{g}$ and $92.55 \%$, respectively.

Table 1 shows that the decision coefficient of the pseudo second-order kinetic model $\left(R^{2}=0.9922\right)$ was obviously better than that of the pseudo first-order kinetic model. The theoretical equilibrium adsorption $q_{\mathrm{e}}$ was relatively close to the measured value $\left(q_{\text {e.exp }}=32.75 \mathrm{mg} / \mathrm{g}\right)$, and the relative error was only $5.78 \%$. Therefore, the pseudo second-order kinetic model could more accurately describe the adsorption process of the sheep manure biochar to MO. In addition, the fitting curve of the particle diffusion model was not passed through the origin point because the related constant $C \neq 0$ indicating particle diffusion had an effect on the adsorption process, but was not the only control rate-limiting step in the adsorption process [24]. The adsorption rate of the process may be controlled by a variety of functions [25].

\section{Isothermal Adsorption and Thermodynamic Analysis}

The influence of initial concentration of MO and temperature on the adsorption effect is shown in Fig. 5. The Langmuir and Freundlich models [26, 27] were used to fit the experimental data and the results are shown in Table 2.

Table 1. Fitting parameters of adsorption kinetic model.

\begin{tabular}{|c|c|c|c|c|c|c|c|c|}
\hline \multicolumn{3}{|c|}{ Pseudo first order kinetic model } & \multicolumn{3}{c|}{ Pseudo second order kinetic model } & \multicolumn{3}{c|}{ Particle diffusion model } \\
\hline$q_{\mathrm{e}}$ & $k_{1}$ & $R^{2}$ & $q_{\mathrm{e}}$ & $k_{2}$ & $R^{2}$ & $C$ & $k_{3}$ & $R^{2}$ \\
\hline 30.674 & 0.0179 & 0.9587 & 34.758 & 0.0007 & 0.9922 & 1.2614 & 8.7873 & 0.8022 \\
\hline
\end{tabular}




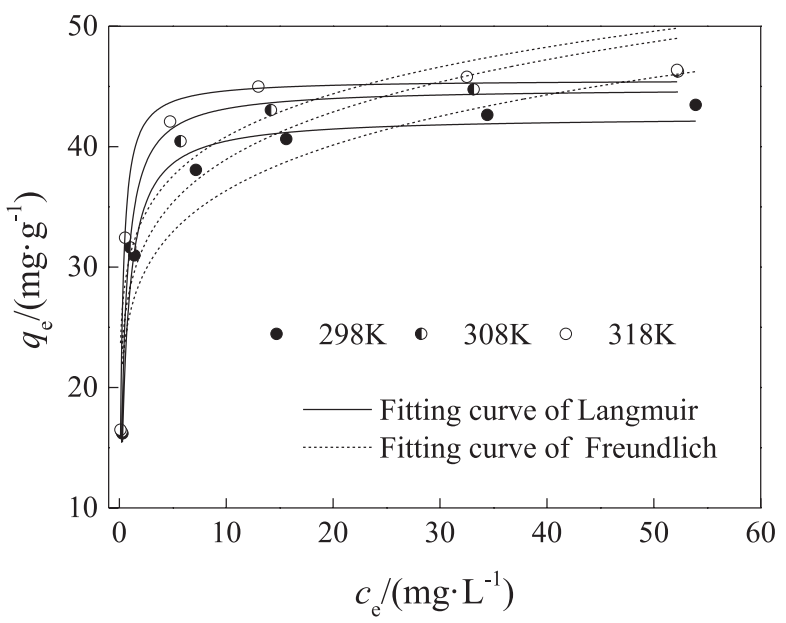

Fig. 5. Fitting curves of isothermal adsorption.

$$
\begin{gathered}
q_{e}=q_{m} k_{L} c_{e}\left(1+k_{L} c_{e}\right) \\
q_{e}=k_{F} c_{e}^{1 / n}
\end{gathered}
$$

$q_{\mathrm{e}}$ adsorption of $\mathrm{MO}$ at equilibrium, $\mathrm{mg} / \mathrm{g}$

$q_{\mathrm{m}:}$ theoretical maximum adsorption of $\mathrm{MO}, \mathrm{mg} / \mathrm{g}$

$c_{\mathrm{e}}$ equilibrium concentration of $\mathrm{MO}, \mathrm{mg} / \mathrm{L}$

$k_{\mathrm{L}:}$ equilibrium constant of Langmuir model, L/mg

$k_{\mathrm{F},} n$ : related constants of Freundlich model

As can be seen from Fig. 5 and Table 2, the Langmuir more accurately described the process of sheep manure biochar adsorption to MO as its decision coefficient $R^{2}$ greater than 0.98 , indicating that the process was mainly single molecular layer adsorption [28] and the theoretical maximum adsorption was $42.513 \sim 45.563 \mathrm{mg} / \mathrm{g}$. It could also be seen that the adsorption capacity increased with the increase of initial concentration of MO and temperature, showing that the increase of initial concentration of $\mathrm{MO}$ and the increase of temperature were favorable to adsorption. The type of adsorption could be further determined according to the formula of separation factor $R_{\mathrm{L}}=1 /\left(1+k_{\mathrm{L}} c_{0}\right)$ [29]. The process belonged to linear adsorption when $R_{\mathrm{L}}$ was 1 , while the adsorption was irreversible when $R_{\mathrm{L}}$ was 0 . It was not a benefit to adsorption when $R_{\mathrm{L}}$ was greater than 1 , while the process was favorable to adsorption when $R_{\mathrm{L}}$ was less than 1 . The $R_{\mathrm{L}}$ range of this experiment was $0.0026 \sim 0.0247$, which indicated that the process was favorable to the adsorption of sheep manure biochar to MO.
In addition, the thermodynamic analysis [30] of the adsorption of biochar to MO was conducted and the results are shown in Table 2.

$$
\begin{gathered}
\Delta G=-R T \ln K_{e} \\
\Delta G=\Delta H-T \Delta S
\end{gathered}
$$

$R$ : ideal gas constant, $8.314 \mathrm{~J} /(\mathrm{mol} \cdot \mathrm{K})$

$T$ : thermodynamic temperature, $\mathrm{K}$

$\Delta G$ : gibbs free energy fluctuation, $\mathrm{kJ} / \mathrm{mol}$

$\Delta S$ : enthalpy change, $\mathrm{kJ} / \mathrm{mol}$

$\Delta H$ : entropy change, $\mathrm{kJ} /(\mathrm{mol} \cdot \mathrm{K})$

$K_{e}$ : thermodynamic equilibrium constant

Table 2 shows that $\Delta G$ was less than 0 , indicating the adsorption of biochar to MO belonged to spontaneous reaction. As the temperature rose, $|\Delta G|$ gradually increased, showing the increase of temperature enhanced the driving force of adsorption, which was beneficial to the adsorption effect. According to relevant references [31], the type of adsorption could be determined by the range of $\Delta \mathrm{G}$. The process belonged to physical absorption when $\Delta G$ ranged from -20 to $0 \mathrm{~kJ} / \mathrm{mol}$, while the adsorption was chemisorption when $\Delta G$ ranged from -40 to $-800 \mathrm{~kJ} / \mathrm{mol}$. Therefore, the adsorption of biochar to $\mathrm{MO}$ in this study was mainly chemical adsorption. $\Delta H$ were greater than 0 , suggesting that the adsorption process was an endothermic reaction [32], and $\Delta S$ were greater than 0 , indicating that there was entropy increase in the adsorption [33].

In recent years, studies on the treatment of $\mathrm{MO}$ wastewater by the adsorption method have been increasing, but research on the adsorption of $\mathrm{MO}$ by biochar has been relatively few. Wang et al. [34] prepared biochar using vermicompost under $600^{\circ} \mathrm{C}$ to adsorb MO in water, and the results showed that the equilibrium absorption capacity of vermicompost biochar to MO was $14.46 \mathrm{mg} / \mathrm{g}$. Yu et al. [35] adopted biochar adsorbent prepared from chicken manure under the pyrolysis $\left(600^{\circ} \mathrm{C}, 120 \mathrm{~min}\right)$ for the removal of $\mathrm{MO}$ in aqueous solution, indicating that the maximum adsorption capacity was $39.47 \mathrm{mg} / \mathrm{g}$ under $25^{\circ} \mathrm{C}$. Table 3 lists the adsorption effect of different types of biochar on MO in water [34-36]. It can be seen that the adsorption amount of MO by sheep manure biochar was at a high value, especially in the same type of animal manure biochar, and the adsorption effect of the sheep manure biochar was better than other types of vermicompost biochar and chicken manure biochar

Table 2. Fitting parameters of isotherm equation and thermodynamics.

\begin{tabular}{|c|c|c|c|c|c|c|c|c|c|}
\hline \multirow{2}{*}{$T / \mathrm{K}$} & \multicolumn{3}{|c|}{ Langmuir equation } & \multicolumn{3}{c|}{ Freundlich equation } & \multicolumn{3}{c|}{ Thermodynamic parameter } \\
\cline { 2 - 10 } & $q_{\mathrm{m}}$ & $k_{\mathrm{L}}$ & $R^{2}$ & $k_{\mathrm{F}}$ & $1 / n$ & $R^{2}$ & $\Delta G$ & $\Delta H$ & $\Delta S$ \\
\hline 298 & 42.513 & 1.9729 & 0.9862 & 26.1764 & 0.1427 & 0.8420 & -7.637 & \multirow{2}{*}{40.056} & \multirow{2}{*}{0.159} \\
\hline 308 & 44.881 & 2.4897 & 0.9870 & 28.2670 & 0.1391 & 0.8354 & -8.795 & & \\
\hline
\end{tabular}


Table 3. Comparison of the adsorption effect of different types of biochar on MO in water.

\begin{tabular}{|c|c|c|c|c|c|}
\hline Adsorbent & $\begin{array}{c}\text { Pyrolysis } \\
\text { temperature } /{ }^{\circ} \mathrm{C}\end{array}$ & $\begin{array}{c}\text { Specific surface } \\
\text { area } / \mathrm{m}^{2} \cdot \mathrm{g}^{-1}\end{array}$ & $\begin{array}{c}\text { Total pore } \\
\text { volume } / \mathrm{cm}^{3} \cdot \mathrm{g}^{-1}\end{array}$ & $\begin{array}{c}\text { Adsorption } \\
\text { capacity } / \mathrm{mg} \cdot \mathrm{g}^{-1}\end{array}$ & References \\
\hline Sheep manure biochar & 600 & 181.76 & 0.245 & $42.513 \sim 45.563$ & This study \\
\hline Vermicompost biochar & 600 & 82.40 & - & 14.46 & {$[34]$} \\
\hline Chicken manure biochar & 600 & - & - & 39.47 & {$[35]$} \\
\hline Pulp and paper sludge(PPS) biochar & 750 & 174 & 40 & 22 & {$[36]$} \\
\hline $\mathrm{FeCl}_{3}$-impregnated PPS biochar & 750 & 15.3 & 3.5 & 46.6 & {$[36]$} \\
\hline
\end{tabular}

at the same pyrolysis temperature. This may be related to the presence of large amounts of plant fibers in the sheep manure, resulting in greater specific surface area or more oxygen-containing functional groups in pyrolyzed biochar. While compared with the biochar from $\mathrm{FeCl}_{3}$-impregnated pulp and paper sludge [36], the preparation process of sheep manure biochar is simpler and does not require a modified process. It is a cheap and easy adsorption material and has a broader application prospect in the field of $\mathrm{MO}$ adsorption.

\section{Conclusions}

The sheep manure biochar prepared by pyrolysis at $600^{\circ} \mathrm{C}$ had good adsorption feasibility. Temperature, initial concentration of $\mathrm{MO}$, initial $\mathrm{pH}$ value and biochar input dosage all had significant effects on the adsorption amount and removal rate of MO by sheep manure biochar. The adsorption process had three different phases, including quick adsorption phase, slow diffusion phase and adsorption equilibrium phase. The pseudo second-order kinetic model more accurately described the adsorption process of biochar to $\mathrm{MO}$, and the Internal diffusion was not the only speed-limit step. The adsorption process of biochar to MO was more consistent with the Langmuir model, which was mainly monolayer adsorption and was favorable to adsorption. Thermodynamic analysis showed that the adsorption was a spontaneous endothermic process of increased entropy and that the temperature increase was beneficial to the adsorption.

\section{Acknowledgements}

This study was financially supported by the Key Project of Education Department in Sichuan Province under grant No. 17ZB0031.

\section{Conflict of Interest}

The authors declare no conflict of interest.

\section{References}

1. HE S., SUN X., ZHANG H. Influence of the protonation state on the binding mode of methyl orange with cucurbiturils. Journal of Molecular Structure, 1107, 182, 2016.

2. SUBBAIAH M.V., KIM D.S. Adsorption of methyl orange from aqueous solution by aminated pumpkin seed powder: kinetics, isotherms, and thermodynamic studies. Ecotoxicology \& Environmental Safety, 128, 109, 2016.

3. RUAN X., CHEN Y., CHEN H., QIAN G., FROST R.L. Sorption behavior of methyl orange from aqueous solution on organic matter and reduced graphene oxides modified $\mathrm{Ni}-\mathrm{Cr}$ layered double hydroxides. Chemical Engineering Journal, 297, 295, 2016.

4. TANZIFI M., HOSSEINI S.H., KIADEHI A.D., MARTINOLAZAR KARIMIPOUR K., REZAIEMEHR R. Artificial neural network optimization for methyl orange adsorption onto polyaniline nano-adsorbent: kinetic, isotherm and thermodynamic studies. Journal of Molecular Liquids, 244, 189, 2017.

5. LI K., LI P., CAI J., XIAO S., YANG H., LI A. Efficient adsorption of both methyl orange and chromium from their aqueous mixtures using a quaternary ammonium salt modified chitosan magnetic composite adsorbent. Chemosphere, 154, 310,2016.

6. XIA K., WANG G., ZHANG H., LIU L., YU Y., WANG L. Synthesis of bimodal mesoporous carbon nanospheres for methyl orange adsorption. Journal of Porous Materials, 24 (6), 1, 2017.

7. YAN SC, LI ZS, ZOU ZG. Photodegradation of Rhodamine $\mathrm{B}$ and Methyl Orange over Boron-Doped g-C3N4 under Visible Light Irradiation. Langmuir, 26 (6), 3894, 2010.

8. WANG S., ZHOU S. Photodegradation of methyl orange by photocatalyst of cnts/p-tio 2, under uv and visible-light irradiation. Journal of Hazardous Materials, 185 (1), 77, 2011.

9. NIRANJAN PANDA, HRUSHIKESH SAHOO, SASMITA MOHAPATRA. Decolourization of methyl orange using Fenton-like mesoporous $\mathrm{Fe}_{2} \mathrm{O}_{3}-\mathrm{SiO}_{2}$, composite. Journal of Hazardous Materials, 185 (1), 359, 2011.

10. WANG Y., GAO Y., CHEN L., ZHANG H. Goethite as an efficient heterogeneous fenton catalyst for the degradation of methyl orange. Catalysis Today, 252, 107, 2015.

11. JIN S.C., PARK S.H., JUNG S.C., RYU C., JEON J.K., SHIN M.C. Production and utilization of biochar: a review. Journal of Industrial \& Engineering Chemistry, 40, 1, 2016. 
12. KEILUWEIT M., NICO P.S., JOHNSON M.G., KLEBER M. Dynamic molecular structure of plant biomassderived black carbon (biochar). Environmental Science \& Technology, 44(4), 1247, 2010.

13. VACCARI F.P., BARONTI S., LUGATO E., GENESIO L., CASTALDI S., FORNASIER F. Biochar as a strategy to sequester carbon and increase yield in durum wheat. European Journal of Agronomy, 34 (4), 231, 2011.

14. WANG J., XIONG Z., KUZYAKOV Y. Biochar stability in soil: meta-analysis of decomposition and priming effects. Global Change Biology Bioenergy, 8 (3), 512, 2016.

15. PARK J.H., OK Y.S., KIM S.H., CHO J.S., HEO J.S., DELAUNE R.D. Competitive adsorption of heavy metals onto sesame straw biochar in aqueous solutions. Chemosphere, 142, 77, 2016.

16. LEHMANN J., RILLIG M.C., THIES J., MASIELLO C.A., HOCKADAY W.C., CROWLEY D. Biochar effects on soil biota-a review. Soil Biology \& Biochemistry, 43 (9), 1812, 2011.

17. MANDAL A., SINGH N., PURAKAYASTHA T.J. Characterization of pesticide sorption behaviour of slow pyrolysis biochars as low cost adsorbent for atrazine and imidacloprid removal. Science of the Total Environment, 577, 376, 2017.

18. SCHIMMELPFENNIG S., GLASER B. One step forward toward characterization: some important material properties to distinguish biochars. Journal of Environmental Quality, 41 (4), 1001, 2012.

19. SPOKAS K.A. Review of the stability of biochar in soils: predictability of o:c molar ratios.Carbon Management, 1 (2), 289, 2010.

20. IBARROLA R., SHACKLEY S., HAMMOND J. Pyrolysis biochar systems for recovering biodegradable materials: a life cycle carbon assessment. Waste Manag, 32 (5), 859, 2012.

21. LIN J., WANG L. Comparison between linear and nonlinear forms of pseudo-first-order and pseudo-second-order adsorption kinetic models for the removal of methylene blue by activated carbon. Frontiers of Environmental Science \& Engineering in China, 3 (3), 320, 2009.

22. CHEN S.H., JIAN Z., ZHANG C.L., YUE Q.Y., YAN L., CHAO L. Equilibrium and kinetic studies of methyl orange and methyl violet adsorption on activated carbon derived from phragmites australis. Desalination, 252 (1), 149, 2010.

23. YAO Y., HE B., XU F., CHEN X. Equilibrium and kinetic studies of methyl orange adsorption on multiwalled carbon nanotubes. Chemical Engineering Journal, 170 (1), 82, 2011.

24. ARAMI M., LIMAEE N.Y., MAHMOODI N.M. Evaluation of the adsorption kinetics and equilibrium for the potential removal of acid dyes using a biosorbent. Chemical Engineering Journal, 139 (1), 2, 2008.
25. BOURAIE M.E., MASOUD A.A. Adsorption of phosphate ions from aqueous solution by modified bentonite with magnesium hydroxide $\mathrm{Mg}(\mathrm{OH})_{2}$. Applied Clay Science, 140, 157, 2017.

26. KANÔ F., ABE I., KAMAYA H., UEDA I. Fractal model for adsorption on activated carbon surfaces: langmuir and freundlich adsorption. Surface Science 467 (1), 131, 2000.

27. HAGHDOOST G., AGHAIE H., MONAJJEMI M. Investigation of langmuir and freundlich adsorption isotherm of $\mathrm{Co}^{2+}$ ion by micro powder of cedar leaf. Oriental Journal of Chemistry, 33 (3), 1569, 2017.

28. LIN R., LIU J., YUE N., DEPAOLI D.W., TAVLARIDES L.L. Kinetics of water vapor adsorption on single-layer molecular sieve 3A: experiments and modeling. Industrial \& Engineering Chemistry Research, 53 (41), 16015, 2014.

29. JIAN M., TANG C., LIU M. Adsorptive removal of $\mathrm{Cu}^{2+}$ from aqueous solution using aerobic granular sludge. Desalination \& Water Treatment, 54 (7), 2005, 2015.

30. GUNASUNDARI E., KUMAR P.S. Adsorption isotherm, kinetics and thermodynamic analysis of $\mathrm{Cu}$ (ii) ions onto the dried algal biomass (spirulina platensis). Journal of Industrial \& Engineering Chemistry, 56, 129, 2017.

31. MASZKOWSKA J., WAGIL M., MIODUSZEWSKA K., KUMIRSKA J., STEPNOWSKI P., BIAŁKBIELIŃSKA A. Thermodynamic studies for adsorption of ionizable pharmaceuticals onto soil. Chemosphere, 111, 568, 2014.

32. EBRAHIMI A., PAJOOTAN E., ARAMI M., BAHRAMI H. Optimization, kinetics, equilibrium, and thermodynamic investigation of cationic dye adsorption on the fish bone. Desalination \& Water Treatment, 54 (11), $1,2015$.

33. GHOSH S.B., BHAUMIK R., MONDAL N.K. Optimization study of adsorption parameters for removal of fluoride using aluminium-impregnated potato plant ash by response surface methodology. Clean Technologies \& Environmental Policy, 18 (4), 1069, 2016.

34. WANG D., GUO H., LI Y., WANG Z., WANG Q., SHEN F. Effects of pyrolytic temperature on methyl orange adsorption by biochar derived from vermicompost. Chinese Journal of Environmental Engineering, 10 (9), 5172, 2016.

35. YU J., ZHANG X., WANG D., LI P. Adsorption of methyl orange dye onto biochar adsorbent prepared from chicken manure. Water Science \& Technology A Journal of the International Association on Water Pollution Research, 77 (5), 1303, 2018.

36. CHAUKURA N., MURIMBA E.C., GWENZI W. Synthesis, characterisation and methyl orange adsorption capacity of ferric oxide-biochar nano-composites derived from pulp and paper sludge. Applied Water Science, 7 (5), 2175, 2017. 